\title{
Derivation of regression equation for estimation of stature by using measurement of femur
}

\author{
Diana Laishram 1 , Shanta Chandrasekaran², Deepti Shastri ${ }^{3}$ \\ ${ }^{1}$ Assistant Professor, Department of Anatomy, Jagannath Gupta Institute of Medical Sciences \& Hospital, Budge \\ Budge, Kolkata, ${ }^{2}$ Professor and Head, Department of Anatomy, Annapoorana Medical College \& Hospital, Salem, \\ Tamil Nadu, ${ }^{3}$ Professor, Department of Anatomy, Vinayaka Mission's Kirupananda Variyar Medical College, Salem, \\ Tamil Nadu
}

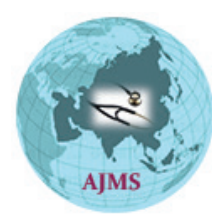

A B S TR A C T

Background: Reconstruction of stature from broken fragments of bones is used as a part of the analysis in forensic anthropology for the purpose of identification of an individual. Long bones are traditionally used for estimation of stature. Long bones such as femur and tibia are the most important components of an individual's stature. In the present study, regression equation was derived for estimation of maximum femoral length from measurements of the proximal end of femur. Aims and Objectives: To derive regression equations using femur length from measurements of neck-shaft angle and maximum vertical diameter of femur head. Materials and Methods: Two hundred unpaired femurs, devoid of gross pathology and irrespective of gender obtained from the Department of Anatomy of both VMKVMC \&VMHMC were used for this study. The correlation coefficients of the neck-shaft angle and maximum diameter of head of femur to the maximum length of femur was calculated. These co-efficient were used for formulation of regression equation. Results: The present study was done to show that the maximum length of femur can be best calculated from the metric evaluation of vertical diameter of the head when the proximal fragments are available. The parameters in our study which includes maximum vertical diameter of the head showed positive correlation but the neck- shaft angle showed a low correlation and is not reliable to measure MFL from it. Conclusion: The present study concludes that the maximum length of femur can be best calculated from the metric evaluation of vertical diameter of the head when the proximal fragments are available.

Key words: Proximal end; Long bone; Stature

\section{INTRODUCTION}

Stature reconstruction from skeletal remains form a part of the forensic anthropological analysis for the purpose of identification of an individual. The estimation of total length of long bones from fragments of the bone was first demonstrated by Muller. ${ }^{1}$ Stature estimation is an important aspect in any medico-legal investigation. This is recapitulated by the fact that research workers had shown vital interests in stature estimation from various skeletal remains for more than hundred years now. The stature of a deceased individual has to be calculated by using the regression equation from the available skeletal materials in the form of incomplete skeleton or isolated long bones or from reconstructed length of long bone from its available fragments for establishing the individual identity of the deceased. According to physical anthropologists, long bones limbs are most suitable to estimate the height of an individual. ${ }^{2}$ The long bones of the lower limb have succumbed consistent and good results. Studies carried out by Pearson ${ }^{3}$ and thereafter Trotter and Glesser ${ }^{4}$ have been monumental and have stimulated subsequent research on the subject. Femur is the longest and largest bone in the human body ${ }^{5,6}$ which shows the highest correlation with

Address for Correspondence:

Dr. Diana Laishram, Department of Anatomy, Jagannath Gupta Institute of Medical Sciences \& Hospital, Budge Budge, Kolkata,

Pin-700060. Mobile: +91-9787472656. E-mail: laishramdiana48@gmail.com 
stature in intact state. ${ }^{7}$ Therefore, the regression formula derived from femur length shows the best assessment of stature.

In order to identify unknown bodies and stature, the knowledge of the morphometric values of femoral segments is important in forensic, anatomic and archaeological cases. Broken fragments of long bones (because of injury, mutilation, destruction, post-mortem gnawing by wild animals) are often presented as the only available source of identity in both archaeological and forensic practice. Thus, the total length of the femur can be estimated from the fragments and later employ them in stature formulae to get reasonably accurate stature. The objective of the present study is to derive regression equations using femur length from measurements of neck-shaft angle and maximum vertical diameter of femur head.

\section{MATERIALS AND METHODS}

Study design followed here is a cross-sectional prospective study carried out for a period of two years in the South Indian Population of Salem, Tamil Nadu.

For the present study a sample of 200 unpaired femur, devoid of gross pathology and irrespective of gender obtained from the Department of Anatomy of both Vinayaka Mission's Kirupananda Variyar Medical College and Vinayaka Mission's Homeopathy College, were used. The sides of the femur were identified.

\section{MATERIALS REQUIRED}

A vernier caliper, goniometer, osteometric board, measuring scale, pencil was used for carrying out the measurements.

\section{Methods}

\section{Femoral neck- shaft angle}

It is the angle made by axis of the shaft with the axis of the upper anterior neck. The neck-shaft angle is measured with the help of a goniometer according to the guidelines given by Singh and Bhasin (1968). ${ }^{8}$ Axis of the neck will be determined by means of a thread which divides the anterior surface of the neck into two equal halves. Axis of the shaft is determined by a thread which extends in the mid-sagittal plane over the anterior surface of the bone from the upper end of the oblique line of the condyles (Figure 1).

\section{Maximum vertical diameter of the femur head (MVDH)}

It is measured by using a vernier caliper at right angle to the long axis of the neck of femur to the superior sagittal diameter of the femur (Figure 2).

\section{Maximum femur length (MFL)}

It is measured from the superior portion of the femoral head to the inferior portion of medial condyle by using osteometric board (Figure 3).

Data will be statistically analysed for regression. Regression equations of the length of the femur against the neck-shaft angle and maximum vertical diameter of the head will be determined. Descriptive statistics were produced on all data using SPSS statistical analysis software. Correlation coefficients were obtained. Correlation coefficient between 0.00 and 0.30 were considered as weak, between 0.300 and 0.700 as moderate and above +0.70 as high.
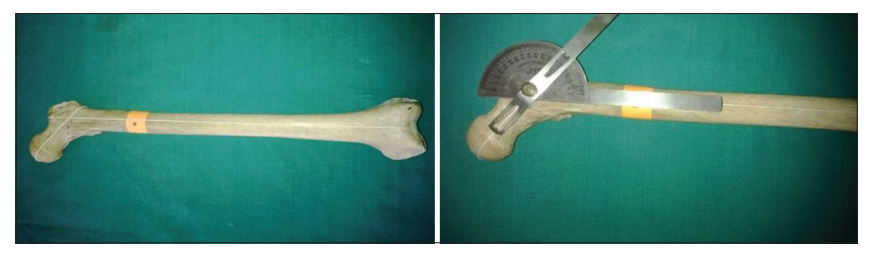

Figure 1: Neck-shaft angle

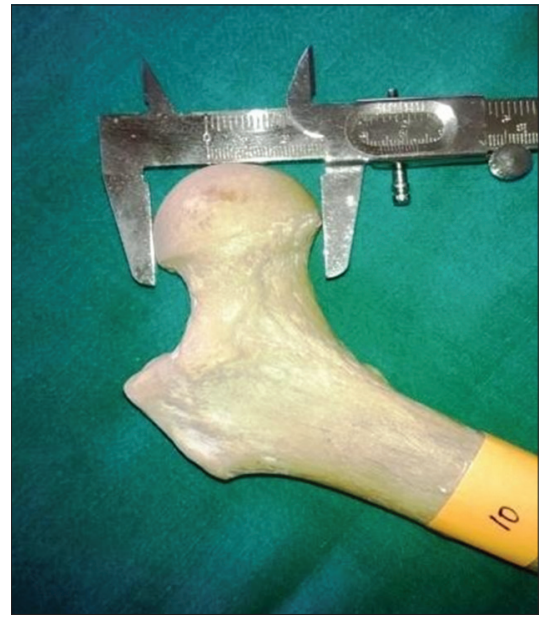

Figure 2: Maximum vertical diameter of the head

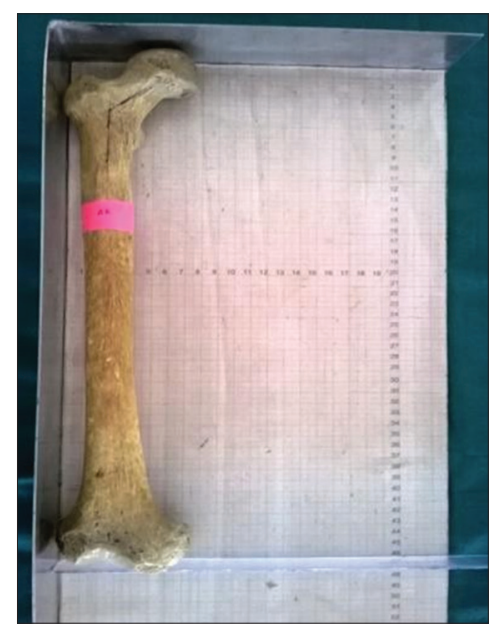

Figure 3: Maximum femur length 
The correlation coefficients of the proximal femoral measurements to the maximum length of femur was calculated.

Regression equations were formulated from these coefficients. In the simple linear regression equations $(y=a+b x), y=M F L, a$ is the intercept, $b$ is the slope, $x$ is the measure of the predictor variable. Regression equation with the maximum length of femur as dependent variable and other measurements as the independent variables were obtained using the total sample $(\mathrm{n}=200)$.

\section{RESULTS}

In the present study, to estimate the length of the femur, the proximal end was identified, measured and regression equations were derived.

Table 1 shows the measurements of different parameters of right and left femur. The mean difference between the minimum and maximum neck-shaft angle is higher on the right side. The mean difference between the minimum \& maximum vertical diameter of the head is same on both the sides. The length of femur ranges from $37.5 \mathrm{~cm}$ to a maximum of $50.7 \mathrm{~cm}$ on the right side \& from $36 \mathrm{~cm}$ to $48.6 \mathrm{~cm}$ on the left side with a mean difference between of $2.14 \mathrm{~cm}$ on the right side $\& 2.28$ on the left side.

Table 2 shows that the co relation co-efficient between right \& left femur is highly significant as it ranges between 0.5 to 0.7 on the right side and between 0.3 to 0.5 on the left side. The neck- shaft angle shows a very poor correlation.

\section{DISCUSSION}

For any medico- legal investigation stature estimation is an important aspect. Pearson pioneered stature estimation from fragments of long bone early in $19^{\text {th }} \& 20^{\text {th }}$ Century. Femur and tibia are the most important components of height estimation of an individual and can be obtained from regression formulae derived from the length of both the bones.

Regression analysis is used for defining the relationship between the length of the long bones and the height of an individual and between the length of the measurements of the long bone fragments and their maximum length.

Apart from estimation of height, the proximal femoral geometry is also important for designing implants. Literature shows a very less statistics about the geometry of proximal femoral in Indian population.

Dynamic hip screw, ASNIS screws, cancellous screws and blade plates are routine implants used for the surgical treatment of proximal femoral fractures. The constitutional and biomechanical factors vary between the Western populations and Indian populations. ${ }^{9}$ In case of total hip arthroplasty, according to Siwach and Noble P.C, it is obligatory that the design and dimensions of the femoral component should match the anatomy of the femur., ${ }^{9}, 10$

Since build, physique, habits and genetic factors vary markedly in different ethnic groups, it is found that anthropometric dimensions described as normal for proximal femur end for Western countries are quite different from those encountered amongst Indians. ${ }^{11}$

The previous studies done on femoral fragment measurements were done irrespective of the side of the femur bone. But in the present study the bones were divided into right and left side femur and the analysis were done separately.

\begin{tabular}{|c|c|c|c|c|c|c|c|c|}
\hline \multirow[t]{2}{*}{ PARAMETERS } & \multicolumn{4}{|c|}{ RIGHT FEMUR } & \multicolumn{4}{|c|}{ LEFT FEMUR } \\
\hline & Minimum & Maximum & S.D & Mean & Minimum & Maximum & S.D & Mean \\
\hline Neck-shaft angle & $120^{\circ}$ & $140^{\circ}$ & 126.5 & 4.87 & $120^{\circ}$ & $145^{\circ}$ & 134.35 & 5.33 \\
\hline Maximum vertical diameter of the head & $3.5 \mathrm{~cm}$ & $4.8 \mathrm{~cm}$ & 4.18 & 0.28 & $3.6 \mathrm{~cm}$ & $4.7 \mathrm{~cm}$ & 4.14 & 0.26 \\
\hline Femur length & $37.5 \mathrm{~cm}$ & $50.7 \mathrm{~cm}$ & 43.21 & 2.14 & $36 \mathrm{~cm}$ & $48.6 \mathrm{~cm}$ & 43.2 & 2.28 \\
\hline
\end{tabular}

\begin{tabular}{|c|c|c|c|c|}
\hline \multirow[t]{2}{*}{ Parameters } & \multicolumn{2}{|c|}{ Right Femur } & \multicolumn{2}{|c|}{ Left Femur } \\
\hline & Regression Equation & $\begin{array}{c}\text { Correlation } \\
\text { Co-Efficient } \\
\text { (R) } \\
\end{array}$ & Regression Equation & $\begin{array}{l}\text { Correlation } \\
\text { Coefficient } \\
\text { (R) }\end{array}$ \\
\hline $\begin{array}{l}\text { Neck- shaft angle } \\
\text { Maximum Vertical } \\
\text { Diameter of the Head }\end{array}$ & $\begin{array}{c}\mathrm{FL}=43.22+0(\mathrm{RNSA}) \\
\mathrm{FL}=42.79+0.006(\mathrm{MVDH})\end{array}$ & $r=0.713$ & $\begin{array}{c}\mathrm{FL}=43.21+0(\mathrm{LNSA}) \\
\mathrm{FL}=43.21+0.0003(\mathrm{MVDH})\end{array}$ & $r=0.498$ \\
\hline
\end{tabular}


Correlation is a measure of association between two variables. In the present study, it is the strength of association of the maximum femur length with the fragments of the proximal end. In our study, the maximum vertical diameter of the femur head showed positive correlation with the maximum femur length. The neck- shaft angle shows a very poor correlation and cannot be reliable to measure MFL from it as shown in Table 1 and 2. It can be used in cases where the other fragments are not available.

While comparing the mean values of the neck-shaft angle of the present study with various authors, it shows highest correlation with the study done by Isaac et al but differs largely from that of Saikia et al (Table 3). ${ }^{12,14}$ The mean value of neck-shaft angle on the right side is $126.5^{\circ}$ and on the left side is $134^{\circ}$. Neck shaft angle of less than $125^{\circ}$ indicates Coxa varus deformity and more than $135^{\circ}$ indicates Coxa valgus deformity. The neck-shaft angle will be greater in females than in males. Therefore, it can also be used for sex determination.

In the present study, the measurement of the maximum vertical diameter of the head have the highest correlation with MFL on both the sides as compared to neck-shaft angle (Table 2). Thus, when the proximal fragment of femur is available, the maximum length of femur can be calculated from the metric evaluation of the maximum vertical diameter of the femur head.

While comparing the correlation coefficient of MVDH in the present study with Simmons et al, the study done by Simmons et al was irrespective of the side of the femur while in the present study it was divided into right and left side femur. The coefficient value is more on the right side in the present study and less on the left side as compared to Simmons et al (Table 4). ${ }^{15}$

Pearson \& Bell found that the MVDH will be typically more than $45 \mathrm{~mm}$ in males and less than $41 \mathrm{~mm}$ in females. ${ }^{16}$

The calculated maximum femoral length can be used to estimate the stature of the individual from the fragments by the regression equations, tables or the multiplication factors already established by various studies.

The maximum length of femur ranged from $37.5 \mathrm{~cm}$ to $50.7 \mathrm{~cm}$ on the right side, with the mean value of $43.21 \mathrm{~cm}$ out of 108 femurs.

The maximum length of femur ranged from $36 \mathrm{~cm}$ to $48.6 \mathrm{~cm}$ on the left side, with the mean value of $43.2 \mathrm{~cm}$ out of 92 femurs (Table 5).

The maximum length of the femur according to Brash is approximately $45.9 \mathrm{~cm}$ in males and $42.6 \mathrm{~cm}$ in females.
According to Pearson \& Bell the values for maximum length of femur is $44.7 \mathrm{~cm}$ in males and $40.9 \mathrm{~cm}$ in females. The relation between stature and the length of long bone shows a difference amongst the three races like Caucasoid, Negro and Mongoloid. Therefore, there is a need to derive separate, specific formulae for different races. ${ }^{4}$ The regression formulae described by Trotter \& Glessor (1958) (Table 6) ${ }^{19}$ for American white, American negroes, Mongoloids \& Mexican populations are given in table 6. The greatest accuracy in estimating living stature from long bones will be obtained when sex and ethnic identity are available. Therefore, it is possible to estimate stature of both male and female individuals from the femoral fragments with reasonable accuracy by these regression equations.

An important shortcoming of the present study is that stature estimation by this approach is based on combining two separate formulae i.e. calculating the femoral length using regression equation and then estimating the stature by multiplying factor. Still, the functions obtained for the end of the femur are of much practical use in cases of fragmented femora in forensic and archaeological purposes.

Further works need to be done to get more accurate estimates in a larger sample considering the age and sex as well. It can

\begin{tabular}{|c|c|c|}
\hline Authors & Population group & Neck- shaft angle \\
\hline Present study & South Indian & $\begin{array}{l}\text { Right- } 126.5^{0} \\
\text { Left-134. } 3^{0}\end{array}$ \\
\hline Isaac $(1993)^{12}$ & South Indian & $126.7^{0}$ \\
\hline Siwach $(2003)^{13}$ & Indian & $123.5^{\circ}$ \\
\hline Saikia $(2008)^{14}$ & North-Eastern Indian & $139.5^{0}$ \\
\hline
\end{tabular}

\begin{tabular}{llcc}
$\begin{array}{l}\text { Table 4: Comparison of the Correlation } \\
\text { Coefficient of MVDH }\end{array}$ & \multicolumn{1}{l}{$\begin{array}{l}\text { No. of } \\
\text { cases }\end{array}$} & MVDH \\
\hline Authors & Race & 800 & 0.596 \\
\hline Simmons (1990) & $\begin{array}{l}\text { American white } \\
\text { population } \\
\text { American Black } \\
\text { population }\end{array}$ & & 0.585 \\
Present study & Indians & 200 & $\begin{array}{c}0.793(\mathrm{Rt}) \\
\& 0.498(\mathrm{Lt})\end{array}$ \\
\hline
\end{tabular}

Table 5: Comparison of the MFL of the present study with other authors

\begin{tabular}{lccc} 
Authors & Race & $\begin{array}{c}\text { No.of } \\
\text { cases }\end{array}$ & MFL \\
\hline Mckern \& Steel $(1969)^{17}$ & Indians & 117 & $44.90 \pm 1.71 \mathrm{~cm}$ \\
Shroff (1999) ${ }^{18}$ & Indians & 200 & $42.01 \pm 2.75 \mathrm{~cm}$ \\
Present study & Indians & 200 & $\begin{array}{c}\text { Rt- } 43.2 \pm 12.41 \mathrm{~cm} \\
\text { Lf- } 43.2 \pm 2.28 \mathrm{~cm}\end{array}$ \\
& & & L \\
& & & \\
\hline
\end{tabular}

Asian Journal of Medical Sciences | Oct 2021 | Vol 12 | Issue 10 


\begin{tabular}{lc}
$\begin{array}{l}\text { Table 6: Regression formulae described for MFL } \\
\text { by Trotter \& Glessor for different population group }\end{array}$ \\
\hline Population & \multicolumn{1}{c}{ Regression formulae } \\
\hline Male Caucasoids & $65.53+2.32$ (femur) $\pm 3.94 \mathrm{~cm}$ \\
Female Caucasoids & $54.10+2.47$ (femur) $\pm 3.72 \mathrm{~cm}$ \\
Male Blacks & $72.22+2.10$ (femur) $\pm 3.91 \mathrm{~cm}$ \\
Female Blacks & $59.76+2.28$ (femur) $\pm 3.41 \mathrm{~cm}$ \\
Male Mongoloids & $72.57+2.15$ (femur) $\pm 3.80 \mathrm{~cm}$ \\
Male Mexicans & $72.57+2.15$ (femur) $\pm 3.80 \mathrm{~cm}$ \\
\hline
\end{tabular}

be considered as a pilot study in obtaining the regression equation to estimate the maximum length of the femur from femoral fragments in a sex and population specific sample.

In the absence of intact long bones, equations presented in the present study can offer a reasonable estimate of maximum femoral length from which the stature can be estimated in different sex and population groups.

\section{CONCLUSION}

The present study concludes that the maximum length of femur can be best calculated from the metric evaluation of vertical diameter of the head when the proximal fragments are available.

\section{ACKNOWLEDGEMENT}

The author takes this opportunity to thank the Department of Anatomy VMKVMC, Salem, both teaching \& non- teaching staffs for their whole hearted support for this study

\section{REFERENCES}

1. Müller G. Zur Bestimmung der Länge beschädigter Extremitätenknochen Anthropol Anz. 1935;12:70-72.

2. Dupertuis $\mathrm{CW}$ and Hadden JA. On the reconstruction of stature from long bones. Am J Phys Anthropol.1951; 9(1):15-54. https://doi.org/10.1002/ajpa.1330090104

3. Karl P. Mathematical Contributions to the Theory of Evolution. V. On the Reconstruction of the Stature of Prehistoric Races. Philosophical Transactions of the Royal Society of London. Series A, Containing Papers of a Mathematical or Physical Character. 1899; 192: 169-244.

https://doi.org/10.1098/rsta.1899.0004
4. Trotter M and Glesser GC. Estimation of Stature from Long Bones of American Whites and Negroes. Am J Phys Anthropol. 1952; 10: 463-514.

https://doi.org/10.1002/ajpa.1330100407

5. Sinnatamby CS. Last's Anatomy: Regional and Applied, London. Churchill Livingstone. 2006;11.

6. Susan S. Gray's Anatomy, The Anatomical Basis of Clinical Practice, Elsevier Churchill Livingstone, London. 2008; 40: 1360-13.

7. Feldesmen MR. Femur. Stature Ratio and Estimates of Stature in Children. A M J Phys Anthropol. 1992; 87(4):447-459. https://doi.org/10.1002/ajpa.1330870406

8. Singh PI and Bhasin ML. Anthropometry, Delhi, Educational Publishers and Booksellers. 1968; 1:142.

9. Siwach RC and Dahiya S. Anthropometric study of proximal femur geometry and its Clinical Application. Indian Journal of Orthopaedics. 2003; 37 (4): 247-251.

10. Noble PC, Jerry W, Alexander JW, Lindahl LJ, Yew DT, Granberry WM, et al. The anatomical basis of femoral component design. Clin Orthop Relat Res. 1988;(235):148-165. https://doi.org/10.1097/00003086-198810000-00015

11. Siwach R. Anthropometric Study of Proximal Femur Geometry and Its Clinical Application. Ann Natl Acad Med Sci (India), 2018;54(4): 203-215.

https://doi.org/10.1055/s-0040-1712831

12. Isaac B. Neck-shaft angle of femur (thesis). Vellore: Tamil Nadu Dr. MGR Uni; 1993.

13. Siwach RC and Dahiya S. Anthropometric Study of Proximal Femur Geometry and Its Application. Indian Journal of Orthopaedics. 2003; 37(4): 247-251.

14. Saikia KC, Bhuyan SK, Rongphar R. Anthropometric Study of the Hip Joint In Northeastern Region Population With CT Scan. Indian J Orthop. 2008; 42: 260-266. https://doi.org/10.4103/0019-5413.39572

15. Simmons $T$, Jantz RL and Bass WM. Stature Estimation from Fragmentary Femora: A Revision of the Steele Method. J Forensic Sci. 1990;35(3):628-636. https://doi.org/10.1520/JFS12868J

16. Pearson $\mathrm{K}$ and Bell $\mathrm{J}$. A study of the long bones of the English skeleton. London, Cambridge University Press; Chicago, University of Chicago Press. 1917.

17. Steele $G$ and McKern T. A method for assessment of maximum long bone length and living stature from fragmentary long bones. Am J Phys Anthropol. 1969; 31:215-227. https://doi.org/10.1002/ajpa.1330310211

18. Shroff AG, Panse AA and Diwan CV. Estimation of length of femur from its fragments. Journal of the Anatomical Society of India. 1999;48(1):1-5.

19. Trotter M and Glessor GC. A reevaluation of estimation of stature based on measurements of stature taken during life and of bones after death. A M J Phys Anthropol. 1958; 16:79-124. https://doi.org/10.1002/ajpa.1330160106

\footnotetext{
Author's contribution:

DL-Data collection, Literature search and review, manuscript preparation and revision, statistically analysis and interpretation; SC-Concept and design, Correction, data analysis and manuscript review; DS-Concept and design, Correction, manuscript review.

Work Attributed to:

Department of Anatomy, VMKVMC, Salem.

Orcid ID-

Dr. Diana Laishram- (1) https://orcid.org/0000-0002-8520-7718

Dr. Shanta Chandrasekaran- 1 https://orcid.org/0000-0002-2675-5327

Dr. Deepti Shastri- ㄴ https://orcid.org/0000-0002-0516-7219

Source of Funding: None, Conflict of Interest: None.
} 